\begin{abstract}
Iranica
Abstracta Iranica Revue bibliographique pour le domaine irano-aryen

Volume 34-35-36 | 2017

Comptes rendus des publications de 2011-2013
\end{abstract}

\title{
Josette Elayi. Histoire de la Phénicie
}

\section{Astrid Nunn}

\section{(2) OpenEdition}

\section{Journals}

Édition électronique

URL : http://journals.openedition.org/abstractairanica/41219

DOI : 10.4000/abstractairanica.41219

ISSN : 1961-960X

Éditeur :

CNRS (UMR 7528 Mondes iraniens et indiens), Éditions de l'IFRI

\section{Référence électronique}

Astrid Nunn, « Josette Elayi. Histoire de la Phénicie », Abstracta Iranica [En ligne], Volume 34-35-36 | 2017, document 100, mis en ligne le 15 juillet 2016, consulté le 27 septembre 2020. URL : http:// journals.openedition.org/abstractairanica/41219; DOI : https://doi.org/10.4000/abstractairanica. 41219

Ce document a été généré automatiquement le 27 septembre 2020.

Tous droits réservés 


\title{
Josette Elayi. Histoire de la Phénicie
}

\author{
Astrid Nunn
}

\section{RÉFÉRENCE}

Josette Elayi. Histoire de la Phénicie. Paris, Perrin, 2013, 342 p., 4 cartes.

1 J. Elayi compte parmi les scientifiques à la plume féconde et a incontestablement contribué à la connaissance historique de la Phénicie. Ce livre en est en quelque sorte le testament.

2 Les Phéniciens ont été redécouverts il y a quelques trois décennies et de nombreuses expositions ont fait connaitre leur art à un grand public. Mais «l'histoire événementielle et socio-économique " est évidemment plus difficile à résumer, et rassembler ce que l'on en sait de sources éparpillées est une bonne chose. L'histoire traitée ici s'étend sur une période qui va de 1200 à 332 av. J.-C., soit du début de l'âge du Fer à la conquête par Alexandre le Grand. Néanmoins la première partie traite de la Phénicie avant 1200, de la préhistoire, de Byblos et L'Egypte, de la genèse des grandes cites phéniciennes et de leur place dans le Proche-Orient (p. 37-96). Suit «La période d'indépendance de la Phénicie (1200-883) » traitée dans la deuxième partie (p. 97-137). «La Phénicie acquiert sa véritable identité vers $1200 »$ (p. 106). L'identité des Phéniciens est difficile à cerner et l'A. la pose à juste titre " en termes de continuité et de discontinuité » (p. 19), une identification par la langue ou quelques marqueurs culturels n'étant pas possible avant le $\mathrm{I}^{\mathrm{er}}$ mill. L'A. aurait pu brièvement rappeler la découverte d'objets égyptiens et égyptisants du Bronze Récent à Kamid el-Loz, qui dans les années 1980 marqua le discours sur l'origine des Phéniciens.

C'est avec la perte de son indépendance en 883 , date à laquelle la domination assyrienne commence, que débute la troisième partie (p. 139-195). La quatrième partie traite de la domination babylonienne (610 à 539) et la cinquième de la domination perse (539-332) (respectivement p. 197-233 et 235-302). Ce sont les périodes sur lesquelles l'A. a le plus travaillé. On note que $40 \%$ des titres cités dans la bibliographie (et même $66 \%$ pour l'époque perse) ont été écrits par elle. Les fameuses œuvres d'art sidoniennes sont 
rapidement évoquées, ce qui est admissible dans un ouvrage historique. L'A. mentionne les « sculpteurs sidoniens » et les « riches Sidoniens qui ont acquis le goût de la culture grecque» (p. 280-281). Il n'est pas hellénocentriste d'ajouter qu'à en juger par la coroplastie et les sceaux, une grande partie de la société sidonienne et phénicienne avait découvert et appréciait « la manière grecque ». L'A. n'est pas la seule scientifique à défendre des vues qui ne soient pas hellénocentristes (p. 13)!

4 À plusieurs reprises les Phéniciens sont présentés comme « inventeurs de l'alphabet » (p. 9, 106). Ceci est pour le moins ambigu, car les Phéniciens n'ont pas inventé l'alphabet mais créé une écriture alphabétique, qui, certes, connaîtra un grand essor. Qu'Hippodamos de Milet, "l'inventeur» du plan urbain orthogonal soit un grec oriental et se soit inspiré des villes palestiniennes, est reconnu depuis longtemps (E. J. Owens, The City in the Greek and Roman World, 1991, 11-31, 51-61). La phrase "Les Phéniciens semblent à l'origine du plan urbain régulier hippodamien» (p. 30-31) est inexacte. Par ailleurs, la métallurgie a été développée si longtemps avant les Phéniciens que la formule «Les Phéniciens passent pour les inventeurs de la métallurgie » (p. 32) mériterait au moins la citation d'une source antique sous peine d'être surprenante. Enfin, les recherches récentes ont montré que la fin de la royauté hittite n'est pas due avant tout aux " Peuples de la mer ", mais à des intrigues internes dont les intrus ont profité. L'assertion « la fin de l'empire hittite est soudaine et imprévisible» (p. 102) est dès lors dépassée.

Malgré ces quelques généralisations qui prêtent à confusion, ce livre offre une synthèse des vues de l'A. agréable à lire.

\section{AUTEURS}

\section{ASTRID NUNN}

Université de Munich 